Jurnal Care Vol .6, No.1,Tahun 2018

\title{
Gambaran Tingkat Pengetahuan Tentang Perawatan Diri (Self Care) Pada Pasien Hemodialisa di RS PKU Muhammadiyah Yogyakarta
}

\author{
Maryudella Afrida ${ }^{1}$, Titih Huriah ${ }^{2}$, Faradisa Yuanita Fahmi ${ }^{3}$ \\ ${ }^{1,2}$ Program Studi Magister Keperawatan Universitas Muhammadiyah Yogyakarta \\ ${ }^{3}$ Akper Muhammadiyah Kendal \\ e-mail : maryudellaafrida89@gmail.com
}

\begin{abstract}
Patients with chronic renal failure 90\% or more will experience kidney function loss, so that hemodialysis routinely is required to maintain fluid and electrolyte balance. Patients with renal failure who undergo hemodialysis routine often experience limitations on self-caring and daily activities, in accordance with Orem's theory stated that the importance of fulfilling self-care needs independently in order to improve the quality of life of patients. The problem of lack of self-care fulfillment is due to the lack of information obtained. The problem of lack of self-care fulfillment is due to the lack of information obtained. The purpose of this study is to describe the level of self-care knowledge for hemodialysis patients in "PKU Muhammadiyah Yogyakarta" Hospital. This research is quantitative descriptive. The total population in this research is as many as 130 people and 38 founded as the research subjects who meet the inclusion criteria of hemodialysis patients who undergo hemodialysis for twice a week. The instrument used in this study is a modified standardized questionnaire. This self-care knowledge questionnaire (self care) consists of 26 items of questions that have been validity tested. Data were analyzed using univariate analysis. The results of this study showed that 31 people $(81.57 \%)$ have less knowledge related to patients self care. It is expected that all kind of health services can provide a sustainable education program in order to improve self-care knowledge in hemodialysis patients.
\end{abstract}

Keywords: Chronic renal failure; knowledge;self care; hemodialysis.

\begin{abstract}
ABSTRAK
Pasien gagal ginjal kronis 90\% atau lebih akan mengalami kehilangan fungsi ginjal, sehingga dibutuhkan tindakan hemodialisa secara rutin untuk mempertahankan keseimbangan cairan dan elektrolit. Pasien gagal ginjal yang menjalani hemodialisa sering mengalami keterbatasan dalam memenuhi perawatan diri dan aktivitas sehari-harinya, sesuai dengan teori yang dikemukakan Orem yang menyatakan pentingnya memenuhi kebutuhan perawatan diri secara mandiri sehingga dapat meningkatkan kualitas hidup pasien. Permasalahan kurangnya pemenuhan perawatan diri ini terjadi akibat minimnya informasi yang diperoleh. Tujuan dari penelitian ini adalah untuk menggambarkan tingkat pengetahuan tentang perawatan diri (self care) pada pasien hemodialisa di RS PKU Muhammadiyah Yogyakarta. Penelitian ini merupakan penelitian deskriptif kuantitatif. Jumlah populasi dalam penelitian ini adalah sebanyak 130 orang dan didapatkan sebanyak 38 subyek penelitian yang memenuhi kriteria inklusi yaitu pasien heemodialisa yang menjalani hemodialisa sebanyak 2 kali dalam seminggu. Instrumen yang digunakan pada penelitian ini adalah kuisioner baku yang dimodifikasi. Kuesioner pengetahuan perawatan diri (self care) ini terdiri dari 26 item pertanyaan yang telah dilakukan uji validitas. Data dianalisis menggunakan analisis univariat. Hasil dari penelitian
\end{abstract}


ini menunjukkan sebanyak 31 orang $(81.57 \%)$ memiliki pengetahuan yang kurang terkait perawatan diri (self care) pasien. Diharapkan agar pelayanan kesehatan dapat memberikan suatu program edukasi yang berkelanjutan dalam rangka meningkatkan pengetahuan perawatan diri pada pasien hemodialisa.

Kata kunci :Gagal ginjal kronis;pengetahuan;perawatan diri;hemodialisa

\section{PENDAHULUAN}

Gagal ginjal kronis (GGK) merupakan gangguan fungsi ginjal yang progresif dan irreversible untuk mempertahankan metabolisme dan keseimbangan cairan elektrolit, sehingga mengakibatkan terjadinya sindrom uremia (Smeltzer \& Bare, 2009). Pasien gagal ginjal kronis akan mengalami kehilangan fungsi ginjal sampai $90 \%$ atau lebih, sehingga kemampuan tubuh untuk mempertahankan keseimbangan cairan dan elektrolit menjadi terganggu, fungsi sekresi menjadi tidak adequat, fungsi hormonal terganggu serta mengakibatkan kondisi uremia atau azotemia sehingga pasien dengan GGK memerlukan adanya terapi penggantian ginjal yang tetap berupa dialisis atau transplantasi ginjal (Nurchayati, 2012).

Hemodialisis merupakan tindakan untuk mengganti sebagian fungsi dari ginjal. Tindakan ini dilakukan secara rutin pada penderita GGK stadium V. Menurut data Indonesia Renal Registry (2012) bahwa jumlah pasien di unit hemodialisa tahun 2012 sekitar 19621 orang pasien baru dan pasien aktif sebanyak 9161 orang. Lebih dari 70\% negara-negara melaporkan sedikitnya 80\% dari pasien menggunakan terapi hemodialisis (Smeltzer \& Bare 2010).

Perawatan diri pasien hemodialisa sudah menjadi perhatian di dunia akibat keterbatasan dalam memenuhi perawatan diri dan aktivitas sehari-harinya. Sesuai dengan teori yang dikemukakan Orem yang menyatakan pentingnya memenuhi kebutuhan perawatan diri secara mandiri sehingga dapat meningkatkan kualitas hidup pasien. Permasalahan ini terjadi akibat minimnya informasi yang diperoleh dari petugas kesehatan selama terapi, mengakibatkan kurangnya informasi dan pengetahuan pasien dan keluarga tentang perawatan diri sehari-hari akibat penyakit dan proses terapi yang dijalaninya (Taylor, 2011).

Kurangnya proses pemahaman dan kesadaran dalam menerima informasi perawatan diri tersebut akan berdampak terhadap pemenuhan kemampuan 
aktivitas sehari-hari serta kualitas hidup pasien...Merujuk pada tingginya prevalensi pasien gagal ginjal yang harus menjalani hemodialisis serta pentingnya perawatan diri pasien hemodialisa di rumah, maka peneliti tertarik untuk melakukan penelitian tentang gambaran pengetahuan perawatan diri (self-care) pasien yang menjalani hemodialisa di rumah.

\section{METODE PENELITIAN}

Penelitian ini merupakan penelitian deskriptif kuantitatif, yang bertujuan untuk mengetahui gambaran tingkat pengetahuan perawatan diri (self care) pasien hemodialisa di RS PKU Muhammadiyah. Jumlah populasi dalam penelitian ini adalah sebanyak 130 orang dan jumlah sampel yang memenuhi kriteeria inklusi dari penelitian ini adalah sebanyak 38 orang. Kriteria inklusi pada penelitian ini adalah pasien hemodialisa yang menjalankan hemodialisa sebanyak 2 kali dalam seminggu, pasien dalam rentang usia 18-45 tahun (usia produktif). sedangkan kriteria eksklusi dari penelitian ini adalah pasien hemodialisa yang mengalami penurunan tingkat kesadaran selama proses penelitian. Teknik sampling yang digunakan adalah consecutive sampling. Sejumlah 38 partisipan penelitian merupakan pasien GGK yang menjalani hemodialisa di Rumah Sakit PKU Muhammadiyah Yogyakarta.Penelitian ini dilaksanakan di Unit Hemodialisis Rumah Sakit PKU Muhammadiyah Yogyakarta pada bulan November Tahun 2017. Untuk mengetahui tingkat pengetahuan pasien digunakan kuisioner pengetahuan perawatan diri pasien hemodialisa di rumah. Kuesioner perawatan diri ini merupakan kuesiner baku dari Keiko (2015) yang dimodifikasi. jumlah butir pertanyaan pada kuesioner ini adalah sebanyak 26 butir pertanyaan yang kemudian dilakukan uji validitas dan realibilitas dengan hasil person product moment dalam kisaran 0.6-0.8 yang berarti memiliki validitas baik dan nilai cronbach alpa 0,853 yang artinya tingkat reliabilitas baik. Analisa data yang digunakan adalah secara univariat. Analisa ini digunakan untuk mendapatkan distribusi frekuensi yang meliputi: umur, jenis kelamin, pendidikan, lama menjalani hemodialisa, dan tingkat pengetahuan pasien terkait perawatan diri pasien hemodialisa dirumah.

\section{HASIL.}

\section{Karakteristik Responden}

Berdasarkan Tabel 1 penelitian didapatkan hasil bahwa lebih dari separuh responden 
penelitian merupakan perempuan dengan presentase $57.9 \%$.

Tabel 2 menunjukkan bahwa separoh responden mempunyai usia 37-45 tahun yakni 24 orang (63,16\%), sedangkan

Tabel 3 menunjukkan bahwa bahwa mayoritas responden penelitian yang menjalani hemodialisa di Unit Hemodialisis PKU Muhammadiyah Yogyakarta memiliki tingkat pendidikan SMA dengan presentase $39.47 \%$ atau sebanyak 15 responden.

Tabel 4 menunjukkan bahwa separoh reponden telah menjalani hemodialisa 1 3 tahun yakni sebanyak 22 responden atau $57.8 \%$. Berdasarkan

Tabel 1. Karakteristik Subyek Penelitian Berdasarkan Jenis Kelamin Di Unit Hemodialisa RS PKU Muhammadiyah Yogyakarta Tahun 2017

\begin{tabular}{lll}
\hline Jenis Kelamin & Jumlah & $\%$ \\
\hline Laki- Laki & 16 & 42.1 \\
Perempuan & 22 & 57.9 \\
\hline Total & 38 & 100 \\
\hline
\end{tabular}

Tabel 2. Karakteristik Subyek Penelitian Berdasarkan Usia Di Unit Hemodialisa RS PKU Muhammadiyah Yogyakarta Tahun 2017

\begin{tabular}{lcc}
\hline Umur & Jumlah & $\%$ \\
\hline $24-30$ tahun & 7 & 18.42
\end{tabular}

\begin{tabular}{lcl}
$31-36$ tahun & 7 & 18.42 \\
$37-45$ tahun & 24 & 63.16 \\
\hline Total & 38 & 100 \\
\hline
\end{tabular}

Tabel 3. Karakteristik Subyek Penelitian Berdasarkan Tingkat Pendidikan Di Unit Hemodialisa RS PKU Muhammadiyah Yogyakarta Tahun 2017

\begin{tabular}{lcc}
\hline Pendidikan & Jumlah & $\%$ \\
\hline SD & 9 & 23.68 \\
SMP & 10 & 26.31 \\
SMA & 15 & 39.47 \\
Perguruan & 3 & 7.89 \\
Tinggi & 1 & 2.65 \\
Tidak Sekolah & & \\
\hline Total & 38 & 100 \\
\hline
\end{tabular}

Tabel 4. Karakteristik Subyek Penelitian Berdasarkan Lama Menjalani Hemodialisa Di Unit Hemodialisa RS PKU Muhammadiyah Yogyakarta Tahun 2017

\begin{tabular}{lll}
\hline $\begin{array}{l}\text { Lama Menjalani } \\
\text { Hemodialisa }\end{array}$ & Jumlah & $\%$ \\
\hline $1-3$ tahun & 22 & 57.8 \\
$3-5$ tahun & 8 & 21.1 \\
$>5$ tahun & 8 & 21.1 \\
\hline Total & 38 & 100 \\
\hline
\end{tabular}

Tabel 5. Tingkat Pengetahuan Responden Tentang Perawatan Diri (Self Care) Pasien Hemodialisa Di Unit Hemodialisa RS PKU Muhammadiyah Yogyakarta Tahun 2017

\begin{tabular}{lcc}
\hline Pengetahuan & Jumlah & $\%$ \\
\hline Kurang & 31 & 81.57 \\
Cukup & 3 & 7.89 \\
Baik & 4 & 10.54 \\
\hline Total & 38 & 100 \\
\hline
\end{tabular}


Tabel 5 diketahui bahwa mayoritas responden penelitian yang menjalani hemodialisa di Unit Hemodialisis RS PKU Muhammadiyah Yogyakarta sebanyak $81.57 \%$ atau sebanyak 31 orang responden memiliki pengetahuan yang kurang terkait perawatan diri (self-care) pasien hemodialisa dirumah.

\section{PEMBAHASAN}

Dari hasil penelitian didapatkan bahwa mayoritas responden penelitian yang menjalani hemodialisa di Unit Hemodialisis RS. PKU Muhammadiyah Yogyakarta memiliki pengetahuan yang kurang terkait perawatan diri (self-care) pasien hemodialisa dirumah $\mathrm{Hal}$ ini menunjukkan rendahnya tingkat pengetahuan pasien gagal ginjal di RS PKU terkait perawatan diri. Pengetahuan adalah hasil penginderaan manusia, atau hasil tahu seseorang terhadap objek melalui indera yang dimilikinya (mata, hidung, telinga, dan sebagainya). Pengetahuan yang dipersepsikan oleh indera tersebut dipengaruhi oleh intensitas perhatian dan persepsi seseorang terhadap objek.Sebagian besar pengetahuan seseorang diperoleh melalui indera pendengaran (telinga), dan indera penglihatan (Notoatmodjo,2007).
Bloom (1956) dalam Potter dan Perry (2006) mengkategorikan pengetahuan menjadi 3 domain, yaitu pengetahuan kognitif, afektif dan psikomotor. Pengetahuan kognitif terkait dengan pemahaman seseorang mengenai suatu hal. Pengetahuan afektif terkait dengan perilaku seseorang setelah memahami sesuatu, sedangkan pengetahuan psikomotor terkait dengan pelaksanaan atas apa yang telah dipahami. Setiap individu memiliki kemampuan dan pemahaman yang berbeda dalam proses memahami dan menterjemahkan suatu informasi, hal ini yang menyebabkan perbedaan pemahaman pada individu yang berbeda. interaksi antara ketiga domain tersebut akan mempengaruhi proses belajar yang optimal. Djannah (2009) dalam penelitiannya di Yogyakarta mengungkapkan bahwa semakin tinggi pengetahuan terhadap suatu objek maka akan semakin baik pula sikap seseorang terhadap objek tersebut.

$$
\begin{aligned}
& \text { Mayoritas responden mempunyai } \\
& \text { pengetahuan yang kurang juga } \\
& \text { diperngaruhi oleh faktor lain, yakni } \\
& \text { pendidikan. Faktor pendidikan dimana } \\
& \text { rata-rata pendidikan responden dalam } \\
& \text { penelitian ini adalah SD, SMP dan SMA. } \\
& \text { sedangkan responden dengan tingkat }
\end{aligned}
$$


pendidikan perguruan tinggi hanya sebanyak 3 responden. Peneliti mengasumsikan tingkat pendidikan mempengaruhi perilaku seseorang dalam mencari perawatan dan pengobatan penyakit yang dideritanya. Pendidikan memiliki pengaruh yang sangat besar dalam mempengaruhi proses belajar dan berpikir seseorang, dimana semakin tinggi tingkat pendidikan seseorang maka akan semakin mudah seseorang dalam menerima suatu informasi. Semakin tinggi pendidikan, individu akan lebih mudah dalam mendapatkan informasi baik dari orang lain maupun dari media massa.

Hal tersebut memungkinkan pasien dapat mengontrol diri dalam mengatasi masalah, mempunyai percaya diri tinggi, berpengalaman dan mempunyai perkiraan yang tepat, mudah mengerti tentang apa yang dianjurkan oleh petugas kesehatan serta dapat mengurangi kecemasan sehingga membantu individu tersebut dalam membuat keputusan.

Pengetahuan seseorang juga dapat dipengaruhi oleh usia. Usia mempengaruhi daya tangkap dan pola pikir seseorang. Semakin bertambah usia seseorang maka akan akan berkembang juga daya tangkap dan pola pikirnya, sehingga akan membantu dalam memperbaiki tingkat pengetahuan orang tersebut. Semakin banyak informasi yang diterima dan aktifitas yang dikerjakan seseorang, akan membantu dalam menambah pengetahuan seseorang. Selain usia, jenis kelamin juga berpengaruh pada pengetahuan seseorang (Budiman, 2013). Asumsi peneliti bahwa tingginya angka responden dengan jenis kelamin perempuan jika dibandingkan dengan responden laki-laki diakibatkan oleh kurangnya tingkat pengetahuan dan pemaparan terkait penyakitnya sehingga menimbulkan ketidak waspadaan pada perempuan sehingga menjadi pencetus terbesar kejadian gagal ginjal kronis.

Pengetahuan seseorang selain dipengaruhi oleh usia, jenis kelamin, pendidikan, lamanya menjalani hemodialisa dapat juga menjadi faktor yang dapat mempengaruhi pengetahuan seseorang terkait perawatan diri (selfcare) pasien hemodialisa dirumah. Dimana hasil penelitian menunjukkan bahwa separoh responden menjalani hemodialisa selama 1-3 tahun. Asumsi peneliti, lamanya menjalani hemodialisa mempunyai pengaruh terhadap kepatuhan pasien dalam menjalankan perawatan terkait kesehatannya. 
Terapi hemodialisa merupakan terapi jangka panjang yang harus diijalani oleh pasien. Lamanya proses terapi mempunyai pengaruh terhadap pengetahuan dan sikap yang berhubungan dengan perawatan diri pada pasien GGK. Setiap penderita memerlukan waktu yang berbeda-beda dalam tingkat pengetahuan dan sikapnya, semakin lama pasien menjalani hemodialisa maka akan banyak pengetahuan yang diperoleh dan bisa bersikap positif terhadap kepatuhan dietnya (Sapri \& Akhmad,2008).

\section{KESIMPULAN}

Mayoritas responden memiliki pengetahuan yang kurang terkait perawatan diri (self-care) pasien hemodialisa dirumah. Diharapkan agar pelayanan kesehatan dapat memberikan suatu program edukasi yang berkelanjutan dan membuat SOP terkait pemberian edukasi terkait perawatan diri dalam rangka meningkatkan pengetahuan perawatan diri pada pasien hemodialisa sehingga dapat membantu dalam mengatasi permasalahan yang sering dihadapi pasien selama menjalani hemodialisa. Selain itu pemberian edukasi ini diharapkan dapat menjadi solusi dalam membantu memandirikan pasien sehingga dapat membantu dalam meningkatkan kualitas hidup dari pasien itu sendiri.

\section{REFERENSI}

Djannah, S.N, Suryani, D dan Purwati, D.A. (2009). Hubungan Tingkat Pengetahuan dan Sikap dengan Perilaku Pencegahan Penularan TBC pada Mahasiswa di Asrama Manokwari Sleman Yogyakarta: Jurnal Kesehatan Masyarakat Vol. 3. No.3. September 2009: 214-221.

Notoatmodjo, S. (2010).Ilmu Prilaku Kesehatan. Jakarta: Rineka Cipta.

Nurchayati S. Hubungan Adekuasi Hemodialisis dengan Kualitas Hidup Pasien Gagal Ginjal Kronik Yang Menjalani Hemodialisis di RSUD Arifin Achmad Pekanbaru. 2014. Available from Proceeding 2015 Riau International Nursing Conference.

Orem, D. E. (2001). Nursing : Concept of practice. (6th Ed.). St. Louis : MosbyInc.

\begin{tabular}{llr} 
Potter & \multicolumn{1}{c}{ Perry.(2006).Buku Ajar } \\
& Fundamental & \\
& Keperawatan.Konsep,Proses, & Dan \\
& Praktik,edisi 4. Volume & 2. \\
& Jakarta:EGC &
\end{tabular}

Sapri, Akhmad. (2008). Asuban Gagal Ginjal Kronik Faktor-faktor yang Mempengarubi Kepatuban dalam Mengurangi Asupan Cairan pada Gagal Ginjal Kronike yang Menjalani Hemodialisa di RSUD Dr. H. Abdul Moeloek Bandar Lampung. Diakses dari http://www/docstoc.com/docs/6 849068/Asuhan Gagal-Ginjal Kronik pada tanggal 22 Oktober 2010 
Jurnal Care Vol .6, No.1,Tahun 2018

Smeltzer, S.C., Bare, B.G., Hinkle, J.L., Cheever, K.H. (2010). Brunner and Suddarth's text book of medical surgical nursing. (11th ed.). Lippincolt
Taylor, R. (2011).Self care science, nursing theory and evidence. New York: Springer Publishing. 